\title{
PEDRO SALINAS: LA LETRA Y LA PERSONA
}

\author{
MONTSERRAT ESCARTín GuAL \\ Universidad de Gerona
}

Se presentan en estas líneas unas cuantas «instantáneas», que no pretenden ser originales ni exhaustivas, pero que pueden contribuir a un más cabal conocimiento del escritor. Pedro Salinas fue un poeta, narrador, dramaturgo y ensayista admirable. Sin duda, un excelente profesor, un gustador del arte, un viajero incansable, un individuo cordial, lleno de buen humor; pero, también, un hombre que padeció un largo exilio de 15 años tras una guerra que le arrancó de su país:

\begin{abstract}
Cuando se haga la paz veré que no tengo ni carrera, ni puesto, ni dinero, ni nombre, que me falta todo eso que he ganado en 40 años de vida y se ha vuelto humo. [...] La energía de mi vida, ahora en el ápice de su fuerza, va a tener que emplearse en mil direcciones de re-construcción exterior, porque la guerra ha caído a mi vida por en medio. Irse a vivir a un país nuevo, o crearse una posición social y profesional nueva, buscar una atmósfera espiritual nueva, es a mi edad, y en mi estado de ánimo, muy duro ${ }^{1}$.
\end{abstract}

Pero, a pesar de la desaparición de tantos bienes, al poeta le afectaron más las pérdidas de otro orden:

¿Qué ha sido de nuestros pobres intentos de reforma, de mejorar la sensibilidad en el siglo XX? Giner, Azorín, Ortega, ¿qué han logrado? Todo perdido. $Y$ se ve uno delante de un horizonte devastado o necio que es peor, de desierto o de estupidez ${ }^{2}$.

Esta preocupación por las convicciones que dan sentido a la vida es, quizá, lo que mejor define a Pedro Salinas. Hoy, al cumplirse cincuenta años de su desaparición - el 4 de diciembre de 1951 - cuando vivimos un momento de cambio e incertidumbre, sin saber cómo llenar el vacío que ha dejado la modernidad, su actitud puede parecer «de otro siglo». Ante

1 Pedro Salinas, Cartas de viaje [1912-1951], Enric Bou (ed.), Valencia, Pre-textos, 1996, pp. 78 y 91 (ambas dirigidas a su esposa, Margarita Bonmatí).

2 Ibídem 76 (a Margarita).

Rlit, LXIV, 128 (2002), 555-566 
nuestro desconcierto, que nos hace sentir como «el hombre sin casa» del que hablaba Rilke, su figura se nos presenta como la de un hombre de valores, coherente, eterno defensor de causas perdidas que lo eran ya en su tiempo y hoy lo son definitivamente.

\section{EL DEFENSOR}

Al inicio de su ensayo, El defensor (1948), Salinas explica que el título traduce su «preocupación por el riesgo en que se ven hoy día algunas formas tradicionales de la vida del espíritu que yo estimo sumamente valiosas», y que él observó amenazadas en los Estados Unidos. Ante el impacto que produjo a su sensibilidad el estilo de vida de los norteamericanos, confiesa:

Un hombre se pasa la vida amontonando millones, mecanizando y materializando a su país y luego le regala museos y bibliotecas, para des-materializarse. Hay como una falta de sentido de la vida que hacen las cosas sin saber por qué, en el fondo. Yo me he podido dar cuenta, por ejemplo, de que no saben lo que es una universidad, ni su finalidad humana. Sus propósitos son excelentes, su intención muy buena, pero les falta algo como el convencimiento interior de lo que hacen [...] Es un país soso espiritualmente [...] viven encerrados en media docena de ideas tontas, fáciles. Es como una falta de originalidad vital, una novedad sólo externa, que disimula la pobreza interior. [...] con una enorme desigualdad entre su cultura material y la espiritual [...] Viviremos bien aquí, lo espero, pero siempre en el fondo de mí habrá, creo, una nostalgia por algo indefinible: la densidad, la antigüedad de lo humano ${ }^{3}$.

De hecho, El defensor es una apología del estilo de vida español frente al americano que impone la prisa, el money maker, las chapuzas. Para Salinas, la diferencia entre «ser en inglés» y «ser en español» es el modo de sentir el tiempo y lo espiritual; es decir, no confundir la cantidad con la calidad:

El lema americano es the bigger is the best. Esto es, cuanto más grande mejor. Pero eso no puede rezar con las cosas más finas y delicadas del hombre. Y si bien han hecho un puente que es el más grande del mundo, mucho me temo que la Universidad sea de las peores, precisamente por su magnitud ${ }^{4}$.

ni elegir la prisa como la mejor pauta de conducta en la vida, bien para hacer dinero rápido o acumular conocimientos leyendo velozmente:

En Norteamérica se llama a un cierto tipo de amante frenético de las riquezas the get rich quick, 'el hacedineros apresurado'. Este hombre arroja toda su energía, bien mondada de escrúpulos y distingos éticos, a la faena de amonto-

\footnotetext{
${ }^{3}$ Ibídem 98 (a Margarita).

${ }^{4}$ Ibídem 132 (a Margarita).
} 
nar dineros a toda prisa y a cualquier costa. En la esfera intelectual también se encuentran acelerados, que todo lo atropellan por añadir cifras y nombres a su haber de lecturas ${ }^{5}$.

Al final del poema Nocturno de los avisos frente al mercantilismo de dicha sociedad que le invita al consumo con anuncios luminosos, el poeta hace toda una declaración de principios, al decidir esperar a:

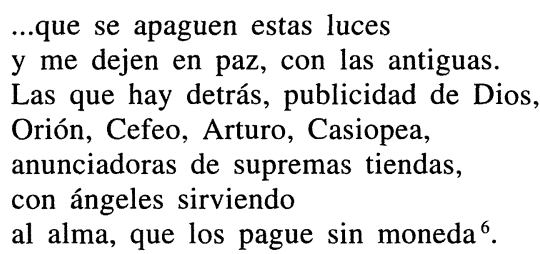

Esa mirada nada materialista es quien le empuja a valorar las acciones no rentables, sea la escritura de una carta, el deleite producido por la contemplación de la naturaleza o de una obra de arte, el valor de la amistad, la lectura... o la simple lentitud:

Hay que arrancar horas al tiempo, como se arrancan margaritas del prado; y para lo peor, para echárselas a los cerdos. [...] Frente a esa moral de la chapuza, hija mestiza de la prisa y el dinero, me atrevo yo a erigir una ética muy modesta» aquella que «dice que cualquier obra delicada y fina del hombre las que valen la pena de ser hombre - tienen su tiempo natural de ejecución, y no se le puede hacer fuerza?

Por este motivo, Salinas se entristecía al ver que las tres gracias clásicas se habían convertido para el siglo XX en «la prisa, la eficacia y el éxito. Las tres hijas del mismo Dios, el dios Praktikós» y que nuestro mundo prefería la tecnología a la naturaleza al sustituir: «auroras con electricidad, y la música de las esferas por la de la radio» ${ }^{8}$.

\section{SOY EL QUE SUEÑA EN ENCONTRAR LA LETRA DE SU CÁNTICO}

Pedro Salinas no escribió un diario, pero sí cartas casi diarias a su esposa (durante su noviazgo y principios de su exilio) y a Jorge Guillén, sobre ideas, cuestiones morales, sentimientos, sensaciones, preferencias estéticas, etc.; en las que reflexionaba, en primera persona y a partir de lo cotidiano, sobre la condición humana o el sentido de la vida. No es de extrañar que eligiera la carta porque ella, como el diario, la autobiografía,

${ }^{5}$ Pedro Salinas, Ensayos completos, II, Madrid, Taurus, 1983, p. 333.

${ }^{6}$ Pedro Salinas, Poesías completas, Barcelona, Seix Barral, 1981, p. 720

7 Pedro Salinas, Ensayos completos, II, op. cit., pp. 246-247.

8 Ibídem 442. 
o cualquier género íntimo, afirma lo que siente el hombre individual y el valor de su espíritu frente a su ser social. Esta actitud y el deseo de profundizar en sí mismo llevó a Salinas al género epistolar, pues escribir sobre lo que se va sintiendo no sólo consiste en explicar lo que a uno le ocurre, sino en dar sentido a los hechos de la vida al interpretarlos. Así, explica: «el primer beneficiado por una carta puede serlo el que la escribe, en cuanto que le asiste al conocimiento de sí mismo» ${ }^{9}$. Razón por la cual el poeta defendió la escritura de las misivas postales, resistiéndose al telegrama - hoy de seguro lo haría ante el correo electrónico- por considerar algo trascendente el acto de escribir al amigo: «la carta actúa como luz, porque luz es el verbo» ${ }^{10}$ y el correo «el comercio de los espíritus» ${ }^{11}$, ya que gracias a ello: «iCuántas gentes superiores han vivido una parte, a veces la totalidad de su persona espiritual, en sus cartas!» ${ }^{12}$. Incluso él, que escribió tantas, renunció a rentabilizar su contenido:

¿Por qué guardas estas cartas aparte? [...] Hay algo en mí que se resiste a la idea de aprovecharlas un día, como depósito de datos. [...] que sean lo más parecido a una conversación, en lo desinteresado y directo. [...] no quisiera nunca, al escribirte, tener otra intención más allá de escribirte; [...] ninguna de las palabras escritas valdrá jamás lo que valen las palabras que me oyes y que te oigo, esas que no se pueden guardar. En ellas está lo más puro de la vida ${ }^{13}$.

De igual manera que redactar una epístola aclara lo que sentimos, la poesía es otro modo de desdoblamiento que permite observarse y comprenderse mejor. Así lo entendió Salinas al afirmar que la poesía es obra de «esclarecimiento» dado que «todo poema digno acaba en iluminaciones» ${ }^{14}$ fundamentalmente de aspectos oscuros del propio yo.

Ya se ha observado cómo el poeta reniega del dios de la cantidad y de la máxima moderna de «más igual a mejor», según la cual «la vida del hombre consistirá en aumentar y no en mejorar, en acrecentar, no en perfeccionar» ${ }^{15}$, ya que las gentes «se mueven antes que por la perfección de su trabajo por despachar, por salir del paso, cumplir; por acabar su faena aunque no la acaben, es decir, la perfeccionen.» Sin embargo, y a pesar de vivir en un mundo donde «no hay tiempo para la perfección» ${ }^{16}$, Salinas declara que su principal tarea es convertirse en la mejor persona posible, esforzarse por lograr ser lo que uno potencialmente puede ser. Parafraseando

${ }^{9}$ Ibídem 242.

10 Ibídem 225.

1 Ibídem 227.

12 Ibídem 445.

13 Pedro Salinas, Cartas de viaje, op. cit., p. 114 (a Margarita).

${ }_{14}$ Pedro SAlinas, Poesías completas, op. cit., p. 656.

15 Pedro Salinas, Ensayos completos, II, op. cit., p. 297.

16 Ibídem 311. 
a Píndaro cuando dice: «Sé lo que eres», en su verso «Ser lo que soy»; o a Goethe: «Sepamos descubrir, aprovechar lo que la naturaleza ha querido hacer de nosotros, lo que ha puesto de mejor en nosotros» ${ }^{17}$; Salinas, en definitiva, aspira a la perfección, aunque la sabe imposible salvo en el voluntarismo, como defendía Maragall, a quien don Pedro admiraba profundamente. Heredero de todos ellos y de las enseñanzas de la Institución Libre de Enseñanza, el poeta usó este criterio para medir la talla de grandes hombres:

\begin{abstract}
...un ejemplo de genio ligero, inconsecuente, descuidado, es Lope de Vega. Te aseguro que toda la simpatía que me inspiran algunas de sus obras se cambia en antipatía si miro todo lo que derrochó y perdió por ligereza: un hombre de genio no tiene derecho a malgastarse, tiene la responsabilidad de un genio, creo yo. [...] esto da idea de lo enorme de la vida, de las innumerables facetas que presenta como un diamante inmenso. Es preciso mirar, mirar siempre no descuidarse y que cada cosa que ante los ojos nos pase, no huya sin dejarnos una belleza o una enseñanza. Hay que ganar la vida espiritual. [...] Quiero hacer de mi alma y mi vida lo mejor que puedan $\operatorname{ser}^{18}$.
\end{abstract}

Con igual fe defendió la ética en los políticos y juzgó duramente a los estadistas de su tiempo, manteniendo siempre una conciencia lúcida ante la historia que le tocó vivir:

...huele a podrido no sólo en Dinamarca, sino en todo el solar de la civilización europea. [...] el deseo de las santísimas democracias es que el caso España se portugalice; es decir, se olvide, y que las gentes no se vuelvan a acordar de que existe una dictadura vergonzosa, ahí en las puertas de Europa ${ }^{19}$.

Anteponiendo a toda forma de gobierno la de sí mismo:

\footnotetext{
...estoy decidido a no ser esclavo de Marx o de Spencer, a no regir los movimientos de mi alma al compás de las revoluciones del mundo, [...] en suma a vivir dentro de mí. Y en cuanto pueda, para los demás. Nada de para los demás en el sentido humanitario de la palabra, en forma de servicio social, no. En sentido humano. Vivir para los seres con quienes la vida me ha puesto en contacto, desde los más cercanos en mi alma, a los estudiantes de mi clase. Ejercer mi acción personal, no a través de teorías abstractas, de partidos o grupos, sino personalmente, sin buscar a la gente ni evitarla. Cada día creo menos en lo político. Y casi diría en lo histórico. La historia no es el hombre. Y creo en otras muchas cosas: el amor, en muchos sentidos de esa palabra; la amistad, la comunicación de las almas; la bondad, el sentido de projimidad, de prójimos, en el mundo; y la infinita riqueza de posibles que guarda este universo. Y lo exterior que siga su curso. Es absurdo estar pen-

17 Ibídem 423.

18 Pedro Salinas, Cartas de viaje, op. cit., p. 37 (a Margarita).

19 Ibídem 99 y 187. (La primera carta va dirigida a Catherine y Juan Centeno y la segunda, a Gustavo Agrait).
} 
sando en la perfectibilidad de los sistemas de gobierno, y abandonarse uno mismo al descuido, a la inercia, al íntimo desgobierno de sí $^{20}$.

Estas palabras revelan que Salinas concibió la vida como un viaje iniciático; además de ser un eterno viajero —en sentido literal— anotando sus sensaciones a través de constantes desplazamientos de los que dan fe sus abundantes epistolarios desde Sudamérica, Europa, Estados Unidos, etc. Sin embargo, a este activismo supo oponer la actitud contraria; es decir, la quietud, la contemplación estática de:

...la naturaleza porque nos devuelve al ser antiguo, al ser de siempre que hay en nosotros, por encima de ese actual y de hoy en que parecemos vivir. Oír los pájaros, los animales, el ruido del aire en los árboles, es repetir en nuestro oído lo que oyeran por siglos y siglos nuestros antecesores ${ }^{21}$.

Aunque defiende que «la forma superior de conocimiento es la contemplación, no la acción» ${ }^{22}$, Salinas es consciente de la dificultad de hacerlo en la época actual, sobre lo cual reflexiona en su obra y en sus cartas:

Lo que a mí me gusta más, ese lento infiltrarse del paisaje en uno, por los ojos, poco a poco, mirándole a gusto, sin prisa y cómodo es casi un imposible. Hacen los americanos con el paisaje lo que con la bebida: se beben todo el vaso de un trago, y a otra cosa. Y mi gusto es dejarme penetrar muy despacio, por las formas y los colores que tengo ante los ojos. [...] mi sensibilidad se ha hecho mucho más apta para la contemplación de las cosas y las ideas. A la par me gustan cada día más las cosas naturales, por ejemplo un árbol, y las ideas claras y originales, los pensamientos reveladores, la luz del $\operatorname{alma}^{23}$.

De entre todos los elementos del entorno natural, el mar ocupó un lugar especial para el poeta al proyectar en él su preocupación trascendente:

...una nostalgia enorme del Mediterráneo. Desde que estoy aquí tengo más y más metido en el alma ese mar y todo lo que representa. Se me figura que es mi verdadero centro de gravedad espiritual ${ }^{24}$.

Este convencimiento se hace poesía en El contemplado (1946), libro donde el mar es el único objeto de admiración y, en cuyos versos, la crítica ha visto cierto misticismo, posiblemente inspirado en las lecturas de San Juan de la Cruz.

Don Pedro no sólo defendió el deleite inmaterial producido por la contemplación de la naturaleza, sino también el despertado por una obra de

${ }^{20}$ Pedro SALINAS, carta de 7.3.1940, guardada en los archivos de Hougthon Library, bMS Span 107 (1), Harvard University. Carpeta 160 (a Katherine Whitmore).

${ }^{21}$ Pedro Salinas, Cartas de viaje, op. cit., p. 118 (a Margarita Bonmatí).

22 Ibídem 109 (a Margarita).

${ }^{23}$ Ibidem 162 y 170 (a Margarita).

${ }^{24}$ Ibídem 84 (a Margarita). 
arte. De su interés por la pintura y los museos, dan muestra su narrativa, situando la acción de Aurora de verdad en la sala de una pinacoteca; su epistolario, donde hay referencias constantes a sus visitas al Prado, Louvre, National Gallery, Fine Art's de Boston... o comentarios de obras y artistas:

...fuimos a un Museo, que no conocía yo, estupendo, con pinturas magníficas. ¡Y siempre lo español, Goya, Velázquez, pero con un acento único e inconfundible, con su fisonomía de alma que no se parece a ninguna! Qué gusto me da encontrarme en los museos, con las caras conocidas, y los espíritus gemelos en esos cuadros! ${ }^{25}$

Esta pasión por el arte también se observa en su poesía, caso del poema Pasajero en museo ${ }^{26}$, donde se muestran las figuras de los lienzos como espíritus inmortales salvados del ajetreo del vivir urbano:

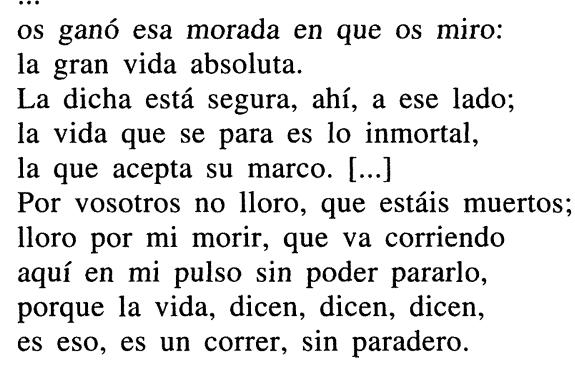

A todo ello hay que sumar aún otro tipo de viaje: el de la creatividad artística hacia el descubrimiento de la propia realidad de escritor, en un proceso que Salinas también necesitó verbalizar en cartas; en ensayos -El poeta y las fases de la realidad-; o en poemas donde encontramos toda una poética, caso de Camino del poema, Confianza o Los signos.

\section{EL HOMBRE SE POSEE EN LA MEDIDA QUE POSEE SU LENGUA}

Coherente con su pensamiento, este «poeta profesor» quiso expresar la fidelidad a unos orígenes, a una lengua, a una tradición a través de su faceta docente. Hizo de la enseñanza del español mucho más que una disciplina académica al sentir, también ante el idioma, una responsabilidad moral:

Lo que llamo educar lingüísticamente al hombre es despertarle la sensibilidad para su idioma, abrirle los ojos a las potencialidades que lleva dentro, persuadiéndole, por el estudio ejemplar, de que será más hombre y mejor hombre si

${ }^{25}$ Ibídem 87 (a Margarita).

${ }^{26}$ Pedro Salinas, Poesías completas, op. cit., pp. 705, 706 y 707. 
usa con mayor exactitud y finura ese prodigioso instrumento de expresar su ser y convivir con sus prójimos ${ }^{27}$.

En la línea de Maragall, Salinas nos dice que el hombre, como ser espiritual, es inseparable de su lenguaje porque a través de la palabra que es espíritu - se construye a sí mismo y se inmortaliza: «El alma humana se confía al lenguaje para traspasar su fatalidad temporal» ${ }^{28}$. Este planteamiento le hizo no estar de acuerdo con algunos filólogos coetáneos, como Leo Spitzer, exiliado también en los Estados Unidos:

[Spitzer] cree que lo mismo da expresarse en un idioma que en otro. Las ideas son las mismas, es verdad. Pero hay algo más que ideas, en la lengua. Y eso es distinto, en cada lengua. ¿Qué parte del hombre está representada en su idioma? ¿Es la mejor, es la peor? ¿Tiene el espíritu un idioma, o no? La dificultad o la imposibilidad de traducir, indican que en las palabras hay una parte de espíritu indisolublemente ligada a ellas, que no se puede $\operatorname{transportar}^{29}$.

Por eso, declara:

La lengua no sirve solamente al hombre para expresar alguna cosa, sino también para expresarse a sí mismo. [...] No habrá ser humano completo, es decir, que se conozca y se dé a conocer, sin un grado avanzado de posesión de su lengua. Porque el individuo se posee a sí mismo, se conoce, expresando lo que lleva dentro, y esa expresión sólo se cumple por el medio del lenguaje [...] el espíritu es lenguaje y se hace por el lenguaje ${ }^{30}$.

La conclusión a la que llega suena sentenciosa: «Persona que habla a medias, piensa a medias, a medias existe» ${ }^{31} \mathrm{y}$ su propuesta sobre el idioma, también:

...este es mi llamamiento: que cuando nosotros se lo pasemos a nuestros hijos, a las generaciones venideras, no sintamos la vergüenza de que nuestras almas entreguen a las suyas un lenguaje empobrecido, afeado o arruinado. Éste es el honor lingüístico de una generación humana, y a él apelo en estas mis últimas palabras ${ }^{32}$.

\section{AMIGo DE SUS AMIGOS...}

Frente al materialismo de la sociedad americana que le acogió, Salinas hace una defensa de principios diversos entre los que destaca la amistad:

La amistad es para mí muy importante en la vida. Y el grupo de mis amigos está escindido y me temo que para siempre. ¡A cuántas cosas hay que decir

\footnotetext{
${ }^{27}$ Pedro SALINAS, Ensayos completos, II, op. cit., p. 439.

28 Ibídem 428.

${ }^{29}$ Pedro SAlinas, Cartas de viaje, op. cit., p. 161.

${ }^{30}$ Pedro SAlinas, Ensayos Completos, II, op. cit., p. 421.

${ }^{31}$ Ibídem 449.

32 Ibídem 456.
} 
adiós! Una de las que más me aterra al pensar en vivir para siempre aquí es el no tener amigos. ¿Cómo hacer amigos, en un país extraño a mi edad? ¿Y con costumbres tan diferentes? [...] cuando uno piensa que este país es el más rico del mundo, y que ellos se lo creen, da risa. Rico, sí, de dinero, de negocios, de cosas materiales. Pero mi riqueza no es esa. $\mathrm{Y}$ al pensar en un viaje de Cádiz a Bruselas, por ejemplo, a través de muchas tierras que parecen pobres se encuentra el alma con la riqueza verdadera, de las mil originalidades del espíritu humano, en diferentes tierras y tiempos, para contestar cada uno a su modo, a las preguntas que todos los hombres oyen en sus conciencias ${ }^{33}$.

Tal vez por ello, la relación Salinas-Guillén fue tan resistente a las circunstancias que les impuso el estilo de vida americano y una tabla de salvación frente a la soledad total que supone sentirse diferente a la que condena cualquier exilio; pero mucho más el que incluye un cambio de cultura:

...te hablo tanto de Jorge Guillén porque su visita ha sido muy importante para mí. Ha reforzado mi fe en la amistad y los sentimientos delicados, como único terreno para poder caminar por este mundo tan hermoso y fascinador, a pesar de toda la ignominia que arrojen sobre él los políticos ${ }^{34}$.

porque, aún en circunstancias difíciles, Salinas siguió defendiendo las relaciones amicales, por encima de las diferencias ideológicas:

¡Cómo me entristece esa noticia de Eusebio [Oliver] y Carmela! Es el único, el primer amigo de verdad mío que está con los rebeldes. [...] amigos eran y amigos son para mí. Amigos serán si ellos quieren serlo. [...] mi amistad le acompaña como siempre. No quiero dejar entrar la guerra civil en mí, eso no. [...] Eusebio está equivocado: lo sé. Pero es noble y bueno, y una equivocación no es una condena de vida. Si algún día le veo le daré un abrazo muy fuerte y ojalá comprenda ${ }^{35}$.

Además del valor de la amistad, el poeta mantuvo hasta el fin de su vida el optimismo como actitud vital, dispuesta a agradecer a cada instante el simple acto de vivir, bromeando incluso sobre su enfermedad:

Lo que más fastidiado me tiene es mi dolencia. No puede ser más pedestre. He tenido que poner los pies en manos de dos médicos, los cuales a su vez pondrán las susodichas manos en mi bolsa, hasta dejarla exhausta. Yo, a fuer de intelectual debía adolecer de la cabeza; pero por lo visto lo que más se usa en este ejercicio del escribir es el otro extremo ${ }^{36}$.

$\mathrm{Y}$, junto a los amigos vivos, los muertos, como recordaba Quevedo desde su exilio en la Torre de Juan Abad ${ }^{37}$ :

\footnotetext{
${ }^{33}$ Pedro Salinas, Cartas de viaje, op. cit., pp. 90, 91 y 167 (a Margarita).

${ }^{34}$ Pedro SALINAS, carta de septiembre de 1938. Houghton Library: carpeta 152 (a Katherine Whitmore)

${ }^{35}$ Pedro Salinas, Cartas de viaje, op. cit., p. 90 (a Margarita).

36 Ibídem 187 (a Gustavo Agrait).

${ }^{37}$ Francisco DE Quevedo, Poesía completa I, Madrid, Turner, 1995, p. 103.
} 
Retirado en la paz de estos desiertos, con pocos pero doctos libros juntos, vivo en conversación con los difuntos $\mathrm{y}$ escucho con mis ojos a los muertos.

Toda la obra de Salinas parte de esta sencilla idea: «somos una conversación», con uno mismo, con los amigos o con los autores favoritos como fuente de la que nutrirse, sobre todo los clásicos, porque:

El que desconoce a los clásicos de su lengua, el que por ignorancia presumida afecta no necesitarlos, se revela como dos veces obcecado, una porque reniega de sus antepasados, de toda esa parte de su ser anterior a su cuerpo mortal, y otra porque lo usa sin saberlo, los lleva dentro ${ }^{38}$.

Motivo por el cual, tanto en su correspondencia privada como en sus ensayos, abundan las referencias a ellos:

...me leí ¿dirás el qué? El banquete de Platón [...] Soberbia lectura para estos días de barbarie y aceleración, de tanque y aeroplano, ésta de un grupo de hombres, disertando sin prisa, en torno a la comida, sobre las cosas más nobles del ánimo ${ }^{39}$.

La defensa de la lectura y el secreto de los libros, ya había sido intuido por el joven Salinas ante la biblioteca de la Sorbona: «iQuién sabe lo que se fragua en esta sala para la vida del espíritu humano!» ${ }^{40}$. Después, como profesor, aplicó ese interés y curiosidad hacia lo más trascendente, como recordaba su amigo Guillén:

...ं de que había menester Pedro Salinas para enseñar literatura? De ganas. Pues las tuvo. A lo largo de su carrera fue a clase dispuesto a pasar una hora deliciosa, precisamente porque en ella ponía su espíritu. [...] 'Nos exigen - decía- que hablemos de literatura. ¿Y encima nos pagan?' ${ }^{41}$

Y, por último, un lugar destacado en la escala de valores de Salinas lo ocupa el amor, el diálogo con el otro yo, esa experiencia inefable gracias a la cual el hombre se convierte en persona. Julián Marías vio en la poesía de Salinas la nueva expresión del amor en el siglo Xx, en cuyo planteamiento, la relación de pareja consistiría en un mutuo ayudarse a expresar lo mejor del ser, aquello que cada uno es en su esencia ${ }^{42}$.

Perdóname por ir así buscándote tan torpemente, dentro de ti.

\footnotetext{
${ }^{38}$ Pedro Salinas, Ensayos completos, II, op cit., p. 437.

${ }^{39}$ Pedro Salinas, Cartas de viaje, op. cit., p. 163 (a Margarita).

40 Ibídem 35 (a Margarita).

${ }^{41}$ Jorge GuilléN, 'Homenaje a Pedro Salinas', Número, 18 (1952), pp. 7 y 8.

${ }^{42}$ Pedro Salinas, Poesías completas, op. cit., p. 285.
} 
Perdóname el dolor, alguna vez.

Es que quiero sacar

de ti tu mejor tú.

motivo por el cual el amante exige trascendencia y no frivolidad al ser amado $^{43}$ :

\author{
Quítate ya los trajes, \\ las señas, los retratos; \\ yo no te quiero así, \\ disfrazada de otra, \\ hija siempre de algo. \\ Te quiero pura, libre, \\ irreductible: tú.
}

Pero no se crea que Salinas excluye la realidad humana del cuerpo, su filografía busca el amor total, porque «Querer vivir es anhelar la carne,/ donde se vive y por la que se muere» ${ }^{44}$, al ser en «esta corporeidad mortal y rosa/ donde el amor inventa su infinito» ${ }^{45}$; dicho de otro modo, el objetivo de la pareja es algo más que la felicidad terrena o el placer, y es, de nuevo, la trascendencia ${ }^{46}$ :

$$
\begin{aligned}
& \text { el ansia de salvarme, de salvarte, } \\
& \text { de salvarnos los dos, ilusionados } \\
& \text { de estar salvando al mismo que nos salva. }
\end{aligned}
$$

Y, si el objetivo no se consigue por la imperfección humana, no importa, porque «es ya la salvación querer salvarnos» ${ }^{47}$; pues, en definitiva, el amor, como la poesía, como todo lo importante para Salinas «es una aventura hacia lo absoluto», por ello el poeta concluye:

Hay que querer algo en este mundo, y consagrarse a ello. Somos lo que queremos. Hay que darse a algo: a un sueño, a un hobby, a un negocio, a un ser humano, a un marido, a un trabajo, a un ideal social. A algo grande que nos salve de esa cosa terrible, de la vida sin propósito, sin más propósito que pequeños placeres y objetivos cortos y limitados ${ }^{48}$.

\footnotetext{
43 Ibídem 243

44 Ibídem 419.

45 Ibídem 329.

${ }^{46}$ Ibídem 339.

47 Ibídem 340.

48 Pedro SALINAS, carta de 17.6.1938. Hougthon Library: carpeta 150 (a Katherine Whitmore).
} 


\title{
RESUMEN
}

\section{Pedro Salinas: la letra y la persona, por Montserrat Escartín Gual.}

Este artículo es un homenaje a Pedro Salinas al cumplirse el cincuentenario de su muerte. En él, se analiza su actitud ante la vida y sus valores a través de sus poesías, cartas personales y ensayos. El poeta critica el materialismo del modelo americano en el que se vio obligado a vivir desde que se exilió hasta su muerte (1936-1951). Frente a la prisa, lo rentable, la tecnología, el dinero..., Salinas cree en su idioma, la lentitud, la amistad, la contemplación del paisaje, el arte, lo espiritual, el optimismo, etc. Hijo de las ideas de la Institución Libre de Enseñanza, su ética personal buscó la mayor perfección a través de la voluntad.

Palabras clave: Pedro Salinas, Biografía, Ideología y literatura.

\begin{abstract}
This article is a Pedro Salinas's homage in the fifty anniversary of his death. Here, we analise his attitude in front of life and his securities through his poems, personal letters and essais. The poet criticizes the materialistic american stil of life, where he should live during his exile until his death (1936-1951). Against the hurry, the profitable things, the technology, the money..., Salinas believes in his language, slowness, friendship, contemplation of countryside, art, spiritualism, optimism, etc. Son of the Institución Libre de Enseñanza's ideas, his personal ethics looked for the biggest perfection trought the will.
\end{abstract}

Key words: Pedro Salinas, Biography, Ideology and literature. 